\title{
Correlation between Mitochondrial Dysfunction, Cardiovascular Diseases, and Traditional Chinese Medicine
}

\author{
Li Zhu, ${ }^{1}$ Zhigang Chen, ${ }^{1}$ Keli Han, ${ }^{1}$ Yilin Zhao, ${ }^{1}$ Yan Li, ${ }^{1}$ Dongxu Li, ${ }^{1,2,3}$ Xiulong Wang, ${ }^{1,2,3}$ \\ Xuefang Li, ${ }^{1,2,3}$ Siyu Sun, ${ }^{1,2,3}$ Fei Lin, ${ }^{1,2,3}$ and Guoan Zhao $\mathbb{D}^{1,2,3}$ \\ ${ }^{1}$ The First Affiliated Hospital of Xinxiang Medical University, Xinxiang 453100, Henan, China \\ ${ }^{2}$ Henan Joint International Research Laboratory of Cardiovascular Injury and Repair, Xinxiang, Henan, China \\ ${ }^{3}$ Henan Engineering Research Center for Mitochondrion Biomedical of Heart, Xinxiang, Henan, China
}

Correspondence should be addressed to Guoan Zhao; guoanzhao@xxmu.edu.cn

Received 30 July 2020; Revised 8 September 2020; Accepted 19 September 2020; Published 8 October 2020

Academic Editor: Yong Wang

Copyright (c) $2020 \mathrm{Li}$ Zhu et al. This is an open access article distributed under the Creative Commons Attribution License, which permits unrestricted use, distribution, and reproduction in any medium, provided the original work is properly cited.

Cardiovascular disease (CVD) is the number one threat that seriously endangers human health. However, the mechanism of their occurrence is not completely clear. Increasing studies showed that mitochondrial dysfunction is closely related to CVD. Possible causes of mitochondrial dysfunction include oxidative stress, $\mathrm{Ca}^{2+}$ disorder, mitochondrial DNA mutations, and reduction of mitochondrial biosynthesis, all of which are closely related to the development of CVD. At present, traditional Chinese medicine (TCM) is widely used in the treatment of CVD. TCM has the therapeutic characteristics of multitargets and multipathways. Studies have shown that TCM can treat CVD by protecting mitochondrial function. Via systematic literature review, the results show that the specific mechanisms include antioxidant stress, regulation of calcium homeostasis, antiapoptosis, and regulation of mitochondrial biosynthesis. This article describes the relationship between mitochondrial dysfunction and CVD, summarizes the TCM commonly used for the treatment of CVD in recent years, and focuses on the regulatory effect of TCM on mitochondrial function.

\section{Introduction}

With the continuous progress in the treatment of infectious diseases and the extension of human life span, the battlefield between humans and diseases has shifted to chronic noncommunicable diseases. Among them, cardiovascular disease (CVD) has become the leading cause of death in China and worldwide as its incidence continues to increase, and it poses a serious threat to the safety and quality of life of patients [1, 2]. Atherosclerosis, hypertension, myocardial ischemia-reperfusion injury, and heart failure are common CVDs or pathological processes. However, the mechanism of their occurrence is not completely clear. An increasing number of studies has shown that mitochondrial dysfunction is closely related to CVD. The mechanisms mainly include oxidative stress disorder, calcium disorder, reduction of mitochondrial biosynthesis, transition of mitochondrial permeability, and accumulation of mitochondrial
DNA mutation. At present, TCM, which has the characteristics of multitargets and multipathways, is widely used in the treatment of CVD [3]. Therefore, in this paper, we discuss the relationship between mitochondrial dysfunction and CVD, as well as the therapeutic mechanism of TCM in the treatment of CVD with respect to mitochondrial function.

\section{Functional Properties of Mitochondria}

Mitochondria are semiautonomous organelles with a unique genetic system that provide the chemical energy required for biosynthesis, respiration, secretion, and mechanical movement in organisms; they are also important organelles that generate intracellular free radicals and regulate apoptosis [4-6]. Mitochondria are known as "capacity factories," "apoptosis switches," and "enzyme bags." They are also called "cellular energy-processing factories" because they 
oxidize three major nutrients to provide adenosine triphosphate (ATP), which is required for life activities [4]. In addition to being energy producers, mitochondria are also the main site of reactive oxygen species [6] (ROS) production. Furthermore, mitochondria also play an important role in the regulation of intracellular calcium homeostasis, calcium-sensitive enzyme activity, and signal transduction [7]. In conclusion, mitochondria are central mediators of energy production, signal transduction, oxidative stress, $\mathrm{Ca}^{2+}$ homeostasis, and apoptosis regulation. Therefore, the normal function of mitochondria is of great importance in life activities.

\section{Mitochondria and Cardiomyocytes}

Cardiomyocytes are highly dependent on aerobic oxidation to supply energy. They contain a considerable amount of mitochondria, up to $20-30 \%$ of cell capacity, which provide more than $90 \%$ of energy to the heart muscle $[8,9]$. The sources of myocardial energy include fatty acids, glucose, and other carbohydrates. These substrates are metabolized in mitochondria, providing energy for cardiomyocytes through oxidative phosphorylation. In fact, $60 \%$ to $90 \%$ of the energy needed by myocardium originates from the ATP produced by aerobic oxidation of fatty acids. Only $10 \%$ to $40 \%$ of the energy is generated by glucose glycolysis and lactic acid oxidation. In addition, the production and utilization of ketone body, ornithine, heme, cardiolipin, and ubiquinone are all related to mitochondria [10].

As a vital functional organelle in myocardial cells, the function of mitochondria is key to elucidating the physiological and pathological changes in CVD, and mitochondrial homeostasis is the core element for maintaining myocardial metabolism, function, and structure [11].

\section{Mitochondrial Homeostasis}

Mitochondrial homeostasis is the steady-state balance between mitochondrial biogenesis and degradation. It involves many aspects such as mitochondrial division and fusion $[6,12]$, mitochondrial crest remodeling $[6,8]$, mitochondrial biosynthesis $[13,14]$, mitochondrial autophagy $[15,16]$, and mitochondrial oxidative stress $[9,17]$. Mitochondrial homeostasis refers to the healthy and stable state of mitochondrial content and metabolism for ensuring the stability of cell energy supply and material metabolism. To maintain the integrity of the mitochondrial structure, mitochondrial division and fusion and mitochondrial crest morphology are altered along with changes in intracellular energy supply [12]. Mitochondrial health is maintained through biosynthesis and autophagy degradation to respond to different energy requirements of cells $[10,15]$. In addition, ROS in mitochondria can be used as signal molecules to activate redox signal molecules through redox reaction, thus participating in the regulation of intracellular signal transduction [18]. Disruption of mitochondrial homeostasis may cause imbalance of mitochondrial motility, lysis of mitochondrial cristae, disruption of mitochondrial biosynthesis, abnormal degradation of mitochondrial autophagy, and oxidative stress in mitochondria. Therefore, the stable state of mitochondrial structure and function has very important physiological significance for the growth, metabolism, and heredity of organisms [19].

\section{Mitochondria Dysfunction and Cardiovascular Diseases}

Mitochondria are the energy factories of cells, and their main function is to consume oxygen and metabolize three major nutrients (sugars, lipids, and amino acids) to produce $\mathrm{CO}_{2}$, water, and energy (ATP) [4]. Cells often need to manage their energy expenditure based on the availability of nutrients and their ability to produce ATP [10]. Disrupted mitochondrial homeostasis will lead to abnormal metabolism of these common substances in the body. Higher organisms need to consume larger amount of energy, and the ATP produced by anaerobic glycolysis is only approximately $1 / 16$ of that produced by aerobic oxidation.

Mitochondria are exposed to various physiological or stress signals, and they produce different signal molecules that affect oxidative stress, apoptosis, autophagy, and inflammation, which are closely related to the occurrence of CVD $[11,16,20]$. The pathophysiological processes of abnormal effects of mitochondria on CVD are reflected in the following aspects: (1) because cardiomyocytes rely on fatty acid-driven oxidative phosphorylation to produce ATP, a decline in the biological efficiency of the mitochondrial network may directly harm the contractility of cardiomyocytes; (2) because $\mathrm{Ca}^{2+}$ flow is the core of overall cardiac activity, incapability of the mitochondrial network to regulate $\mathrm{Ca}^{2+}$ homeostasis can alter cardiac function; (3) physiological inflammatory homeostasis has a certain protective effect not only on cardiac function but also on vascular filling, but the accumulation of damaged mitochondria in the cytoplasm of cardiomyocytes or endothelial cells can cause pathogenic inflammation; and (4) the integrity of the cardiovascular system is essential for cardiac contractile and circulatory functions. Severe mitochondrial dysfunction and accumulation of damaged mitochondria initiate a series of cell death that eventually leads to pathological damage.

\section{Mitochondrial Dysfunction and Atherosclerosis}

Atherosclerotic (AS) is the main cause of death due to cardiovascular disease. In patients with mitochondrial dysfunction, decreased activity of progressive respiratory chain enzymes, excessive production of ROS, and cumulative mitochondrial DNA (mtDNA) damage or mutations are closely related to the occurrence and development of atherosclerosis $[21,22]$. Studies have shown that oxidized low-density lipoprotein (ox-LDL) plays an important role in the occurrence and development of atherosclerosis; ROS produced by mitochondria and its modified ox-LDL are involved in all pathological processes of atherosclerosis [23]. Ox-LDL can slow down the electron transport of mitochondrial respiratory 
chain by inhibiting the activity of mitochondrial respiratory enzymes and increasing the formation of ROS, thus forming a vicious circle and promoting endothelial injury and atherosclerosis [23]. It was found that when the activity of Mn-SOD $\left(\mathrm{SOD}_{2}\right)$ decreased, mtDNA damage increased in apoE ${ }^{-/-}$rats, which preceded the formation of atherosclerotic plaques. As oxidative stress in mitochondria increased, atherosclerotic lesions were significantly aggravated [24]. In addition, studies in apoE ${ }^{-/-}-\mathrm{SOD}_{2}^{+/-}$mice have shown that an increase in mitochondrial ROS not only promoted the formation of atherosclerotic plaques but also increased the susceptibility of the body to atherosclerotic risk factors [25]. Moreover, mtDNA damage caused by DNA repair dysfunction can directly accelerate atherosclerosis in apoE ${ }^{-/-}$rats and promote diabetic atherosclerotic complications. Furthermore, transient opening of mitochondrial permeability transition pore (mPTP) can depolarize mitochondrial membrane potential, whereas long-term opening of mPTP leads to matrix swelling, rupture of mitochondrial outer membrane, and apoptosis. Both of these changes can promote the occurrence and development of atherosclerosis [21, 22]. In an experiment using wild-type mice, it was found that aging led to increases in IL-6 level and mitochondrial dysfunction. Hyperlipidemia further decreased the mitochondrial function and increased the level of Parkin in the aorta of old mice (16 months of age). Importantly, oral spermidine can enhance the mitotic function of aged hyperlipidemic mice, prevent elevation of aortic IL-6 and Parkin levels, reduce mitochondrial dysfunction, and reduce atherosclerosis formation. Overall, new treatments that improve vascular mitochondrial bioenergetics or reduce inflammation before hyperlipidemia may reduce age-related atherosclerosis [26]. Overall, oxidative stress, inflammatory reaction, and mitochondrial dysfunction play a key role in the formation of atherosclerosis. Mitochondria-targeted antioxidant and anti-inflammatory therapies may have great prospects for the treatment of atherosclerosis [27].

\section{Mitochondrial Dysfunction and Hypertension}

Hypertension is a common CVD in modern society. Many studies have shown that mitochondrial dysfunction is closely related to hypertension [28]. The superoxide anions produced by mitochondria can oxidize the NO released by endothelial cells, decrease the endothelium-dependent vasodilation function, increase vascular force, and increase blood pressure. Uncoupling of mitochondrial oxidative phosphorylation caused by UCP2 gene polymorphism or altered expression is also associated with high blood pressure [29]. In addition, the lack of mitochondrial productivity, calcium overload, and mitochondrial DNA mutations are all involved in the pathological process of arterial hypertension and hypertensive heart disease. Angiotensin II (Ang II) plays an important role in the development of hypertension. Ang II can also inactivate the NO produced by endothelial cell by stimulating the production of mitochondrial ROS, resulting in vascular endothelial dysfunction [30]. Mitochondrial dysfunction is also related to dysfunction of blood pressure regulation center [31]. Related research has confirmed that mitochondrial dysfunction caused by maternally inherited mitochondrial transfer ribonucleic acid (tRNA) mutations is associated with the development of essential hypertension [32]. Otherwise, under the conditions of inflammation, Ang II stimulation, and metabolic syndrome, disturbances in mitochondrial biogenesis and mitochondrial bioenergetics in the brain will lead to the accumulation of ROS, which plays an active role in the pathophysiology of ROS-related neurogenic hypertension [33]. Overall, increased ROS production, decreased ATP production, and calcium overload play an important role in the occurrence and development of hypertension. Moreover, mitochondrial gene polymorphism and mitochondrial tRNA gene mutations are also associated with hypertension.

\section{Mitochondrial Dysfunction and Myocardial Ischemia-Reperfusion Injury}

Myocardial ischemia-reperfusion injury (IR injury) is common in reperfusion therapy after acute myocardial infarction, manifesting as arrhythmia, reduced cardiac systolic function, and other phenomena. Mitochondrial energy metabolism disorder is an important factor causing myocardial IR injury [34]. The main mechanisms include reduced mitochondrial ATP production and excessive ROS production, causing oxidative stress, $\mathrm{Ca}^{2+}$ overload, and sustained mPTP opening $[18,35]$. Excessive ROS production during ischemic myocardial reperfusion is the main cause of myocardial IR injury, and mitochondria are an important source of ROS. On the one hand, increased ROS can damage the mitochondrial membrane system, which affects the mitochondrial membrane potential and disrupts mitochondrial ATP synthesis. On the other hand, mitochondria produce excessive ROS, which causes peroxidation of proteins and lipids and damage to the mitochondrial membrane, further decreasing the activity of the electron transport chain enzymes, which in turn form a vicious circle that eventually leads to cardiomyocyte apoptosis and necrosis [36]. In addition to excessive ROS, myocardial ischemia-reperfusion-induced cell $\mathrm{Ca}^{2+}$ overload is an important cause of myocardial IR injury [18, 35]. Persistent opening of mitochondrial mPTP with high permeability also plays an important role in IR injury. This causes the entrance of numerous small molecules to mitochondria, resulting in the swelling of mitochondria, rupture of the outer membrane, collapse of membrane potential, and release of various proapoptotic factors to induce cell apoptosis or death [35]. Taken together, improving mitochondrial function, reducing oxidative stress caused by excessive production of mitochondrial ROS, preventing intracellular calcium overload, and preventing the opening of mitochondrial mPTP are effective measures for the prevention and treatment of IR injury.

\section{Mitochondrial Dysfunction and Heart Failure}

Heart failure (HF) is the final stage of the development of various CVDs, such as myocardial infarction, hypertension, and cardiomyopathy. The relationship between mitochondrial 
TABLE 1: Regulatory effects of active components of TCM on mitochondria.

\begin{tabular}{|c|c|c|c|c|c|}
\hline Category & $\begin{array}{l}\text { Chemical } \\
\text { components of } \\
\text { TCM } \\
\end{array}$ & Monomer source & $\begin{array}{l}\text { Molecular } \\
\text { formula }\end{array}$ & Mechanism of action & Reference \\
\hline \multirow{6}{*}{$\begin{array}{l}\text { Restoratives for } \\
\text { invigorating qi }\end{array}$} & $\begin{array}{l}\text { Ginsenoside } \\
\text { compound } \mathrm{K}\end{array}$ & Radix ginseng & $\mathrm{C}_{36} \mathrm{H}_{62} \mathrm{O}_{8}$ & $\begin{array}{l}\text { Inhibition of nuclear factor-B } \kappa, \mathrm{p} 38 \text {, and } \\
\text { JNK MAPK pathways }\end{array}$ & $\begin{array}{l}\text { Lu et al. } \\
\text { [43] }\end{array}$ \\
\hline & & & & $\begin{array}{l}\text { Regulation of NF- } \kappa \mathrm{B} / \mathrm{PGC}-1 \alpha \text { signaling- } \\
\text { mediated energy biosynthesis }\end{array}$ & $\begin{array}{l}\text { Zhang et al. } \\
\text { [44] }\end{array}$ \\
\hline & Astragaloside IV & Radix Astragali & $\mathrm{C}_{41} \mathrm{H}_{68} \mathrm{O}_{14}$ & $\begin{array}{c}\text { Downregulation of miR-23a and miR-92a- } \\
\text { activated PI3K/AKT and MAPK/ERK } \\
\text { signaling pathways }\end{array}$ & $\begin{array}{l}\text { Gong et al. } \\
\text { [45] }\end{array}$ \\
\hline & & & & $\begin{array}{l}\text { Stimulation of fatty acid } \beta \text {-oxidation and } \\
\text { improvement of mitochondrial function }\end{array}$ & $\begin{array}{l}\text { Dong et al. } \\
\quad[46]\end{array}$ \\
\hline & $\begin{array}{c}\text { Astragalus } \\
\text { polysaccharides }\end{array}$ & Radix Astragali & $\mathrm{C}_{10} \mathrm{H}_{7} \mathrm{C}_{1} \mathrm{~N}_{2} \mathrm{O}_{2} \mathrm{~S}$ & Inhibition of apoptosis & $\begin{array}{l}\text { Liu et al. } \\
\quad[47]\end{array}$ \\
\hline & Salidroside & $\begin{array}{l}\text { Rhodiola } \\
\text { crenulata }\end{array}$ & $\mathrm{C}_{14} \mathrm{H}_{20} \mathrm{O}_{7}$ & $\begin{array}{l}\text { Activation of a mitochondria-associated } \\
\text { AMPK/PI3K/Akt/GSK3 } \beta \text { pathway }\end{array}$ & $\begin{array}{c}\text { Zheng et al. } \\
{[48]}\end{array}$ \\
\hline \multirow{2}{*}{$\begin{array}{l}\text { Restoratives for } \\
\text { nourishing yin }\end{array}$} & Ophiopogonin D & $\begin{array}{c}\text { Radix } \\
\text { Ophiopogonis }\end{array}$ & $\mathrm{C}_{44} \mathrm{H}_{70} \mathrm{O}_{16}$ & Antioxidant and antiapoptotic effects & $\begin{array}{l}\text { Huang et al. } \\
{[49]}\end{array}$ \\
\hline & Ecliptal & Eclipta alba & - & $\begin{array}{l}\text { Activation of the Wnt-pathway and } \\
\text { alteration of AKT signaling }\end{array}$ & $\begin{array}{l}\text { Yang et al. } \\
\text { [50] }\end{array}$ \\
\hline \multirow{2}{*}{$\begin{array}{l}\text { Restoratives for } \\
\text { nourishing yang }\end{array}$} & Velvet antler & $\begin{array}{l}\text { Cornu cervi } \\
\text { pantotrichum }\end{array}$ & - & $\begin{array}{l}\text { Regulation of the PI3K/Akt signaling } \\
\text { pathway and mitochondrial membrane } \\
\text { potential }\end{array}$ & $\begin{array}{l}\text { Xiao et al. } \\
\quad[51]\end{array}$ \\
\hline & Icariin & Herba Epimedii & $\mathrm{C}_{33} \mathrm{H}_{40} \mathrm{O}_{15}$ & $\begin{array}{l}\text { Activation of sirtuin-1/FOXO1 signaling } \\
\text { and improvement of mitochondrial } \\
\text { membrane homeostasis }\end{array}$ & $\begin{array}{l}\text { Wu et al. } \\
\quad[52]\end{array}$ \\
\hline
\end{tabular}

dysfunction and HF is mainly reflected as follows: the disturbance of mitochondrial energy metabolism plays an important role in the occurrence and development of HF. During HF, mitochondrial ATP synthesis decreased, and ROS production increased, whereas the disturbance of energy metabolism in myocardial mitochondria aggravated the disruption of cardiac mechanical function and deterioration of cardiac function. ROS modified myofibrillar protein in the myocardium via oxidation, resulting in a progressive decrease in cardiac contractile function and irreversible cardiac injury $[37,38]$. Studies in an experimental HF model have shown that the expression of myocardial mitochondrial biosynthesis factor is downregulated, whereas mtDNA content is reduced, which not only results in reduced mitochondrial biosynthesis but also causes mitochondrial oxidative phosphorylation and reduces the ability of mitochondria to oxidize fatty acids, which leads to deficiencies in myocardial energy production and HF development [39]. In patients with congenital heart disease, damage in $\mathrm{mtDNA}$ replication leads to the loss of right ventricular mtDNA, resulting in the progression of heart hypertrophy to HF [40, 41]. Therefore, to prevent mitochondrial damage and maintain the integrity of its function, reducing oxidative stress will be an important strategy in the treatment of HF [41].

In summary, the maintenance of mitochondrial homeostasis is very important in life activities, and mitochondrial dysfunction is closely related to the occurrence and development of CVD. TCM is widely applied in the clinical treatment of CVD, and mitochondria are the intracellular targets of many kinds of drugs. Thus, we propose that TCM can treat CVD by affecting mitochondrial homeostasis.

\section{Protective Effect of TCM on Myocardial Mitochondria}

Mitochondria play a significant role in the regulation of physiological function and pathological process in the cardiovascular system [11]. TCM [42], including the chemical components, single herbs, and compound medicines, can treat CVD by regulating the function of mitochondria, which will be described below.

10.1. Chemical Components of TCM. The chemical components of TCM are the substance bases of its pharmacology. The composition of TCM is extremely complex, as each TCM contains many kinds of chemical components. Components that have biological activity and play a role in the prevention and treatment of diseases are known as effective components. Modern studies have shown that the effective components of TCM can protect cardiomyocyte mitochondria in many ways. Several common drugs are summarized in Tables 1-4.

10.2. Single Herbs of TCM. Single herbs are a type of TCM. Different single herbs have different curative effects, but they may have the same drug action. A single herb can have many different effects. Previous studies have shown that some single-herb medicines can treat coronary heart disease (CHD) by affecting mitochondrial homeostasis. Several common drugs are summarized in Table 5. 
TABLE 2: Regulatory effects of the active components of traditional Chinese medicine on mitochondria for promoting blood circulation and removing blood stasis.

\begin{tabular}{|c|c|c|c|c|}
\hline $\begin{array}{l}\text { Chemical components of } \\
\text { TCM }\end{array}$ & Monomer source & $\begin{array}{l}\text { Molecular } \\
\text { formula }\end{array}$ & Mechanism of action & Reference \\
\hline $\begin{array}{l}\text { Panax notoginseng } \\
\text { saponins }\end{array}$ & Radix Notoginseng & $\mathrm{C}_{47} \mathrm{H}_{80} \mathrm{O}_{17}$ & $\begin{array}{l}\text { Attenuation of oxidative stress and cardiomyocyte } \\
\text { apoptosis }\end{array}$ & $\begin{array}{l}\text { Zhang et al. } \\
\text { [53] } \\
\text { Zhou et al. } \\
\text { [54] }\end{array}$ \\
\hline Notoginsenoside R1 & Radix Notoginseng & $\mathrm{C}_{54} \mathrm{H}_{92} \mathrm{O}_{24}$ & Elevation of mitochondrial ATP synthase $d$-subunits & He et al. [55] \\
\hline Salvianolic acid A & $\begin{array}{l}\text { Radix Salviae } \\
\text { Miltiorrhizae }\end{array}$ & $\mathrm{C}_{26} \mathrm{H}_{22} \mathrm{O}_{10}$ & Promotion of myocardial mitochondria biogenesis & $\begin{array}{l}\text { Zhang et al. } \\
\text { [56] }\end{array}$ \\
\hline Salvianolic acid B & $\begin{array}{l}\text { Radix Salviae } \\
\text { Miltiorrhizae }\end{array}$ & - & Improvement of mitochondrial biogenesis & Pan et al. [57] \\
\hline Tanshinone IIA & $\begin{array}{l}\text { Radix Salviae } \\
\text { Miltiorrhizae }\end{array}$ & $\mathrm{C}_{19} \mathrm{H}_{18} \mathrm{O}_{3}$ & $\begin{array}{l}\text { Upregulation of } 14-3-3 \eta \text {, prevention of mPTP } \\
\text { opening, and inhibition of apoptosis }\end{array}$ & $\begin{array}{l}\text { Zhang et al. } \\
\text { [58] }\end{array}$ \\
\hline Dihydronortanshinone & $\begin{array}{l}\text { Radix Salviae } \\
\text { Miltiorrhizae }\end{array}$ & - & $\begin{array}{l}\text { Anti-inflammatory effect via the NF- } \kappa \text { B, } \\
\text { mitochondrial ROS, and MAPK pathways }\end{array}$ & Wu et al. [59] \\
\hline Curcumin & $\begin{array}{l}\text { Rhizoma Curcumae } \\
\text { Longae }\end{array}$ & $\mathrm{C}_{21} \mathrm{H}_{20} \mathrm{O}_{6}$ & $\begin{array}{c}\text { Antioxidant and anti-inflammatory activities } \\
\text { Mitochondrial stress and substrate switching } \\
\text { inhibition }\end{array}$ & Li et al. [60] \\
\hline
\end{tabular}

TABLE 3: Regulatory effects of the active components of interior warming medicines on mitochondria.

\begin{tabular}{|c|c|c|c|c|}
\hline $\begin{array}{l}\text { Chemical components } \\
\text { of TCM }\end{array}$ & $\begin{array}{l}\text { Monomer } \\
\text { source }\end{array}$ & $\begin{array}{l}\text { Molecular } \\
\text { formula }\end{array}$ & Mechanism of action & Reference \\
\hline \multirow{2}{*}{ Flavonoid glycosides } & Fenugreek & - & Regulation of glycolipid metabolism & $\begin{array}{l}\text { Luan et al. } \\
\text { [61] }\end{array}$ \\
\hline & $\begin{array}{l}\text { Rhizoma } \\
\text { Zingiber }\end{array}$ & $\mathrm{C}_{17} \mathrm{H}_{26} \mathrm{O}_{4}$ & $\begin{array}{c}\text { Improvement of ectopic lipid accumulation, mitochondrial } \\
\text { dysfunction, and insulin resistance }\end{array}$ & Liu et al. [62] \\
\hline
\end{tabular}

TABLE 4: Regulatory effects of the active components of other traditional Chinese medicines on mitochondria.

\begin{tabular}{|c|c|c|c|c|}
\hline Type of TCM & Monomer source & $\begin{array}{l}\text { Molecular } \\
\text { formula }\end{array}$ & Mechanism of action & Reference \\
\hline Triptolide & Tripterygium wilfordii & $\mathrm{C}_{21} \mathrm{H}_{28} \mathrm{O}_{6}$ & $\begin{array}{l}\text { Regulation of mitochondrial membrane } \\
\text { permeabilization }\end{array}$ & Xi et al. [63] \\
\hline Oxymatrine & $\begin{array}{l}\text { Radix Sophorae } \\
\text { Flavescentis }\end{array}$ & $\mathrm{C}_{16} \mathrm{H}_{26} \mathrm{~N}_{2} \mathrm{O}_{2}$ & Inhibition of cardiac apoptosis and oxidative stress & $\begin{array}{l}\text { Zhang et al. } \\
\text { [64] }\end{array}$ \\
\hline $\begin{array}{l}\text { Epigallocatechin } \\
\text { gallate }\end{array}$ & Green tea & $\mathrm{C}_{22} \mathrm{H}_{18} \mathrm{O}_{11}$ & $\begin{array}{c}\text { Inhibition of deterioration of mitochondrial structure } \\
\text { and function by OMA1 }\end{array}$ & Nan et al. [65] \\
\hline Cyclovirobuxine D & Buxus microphylla Sieb & $\mathrm{C}_{26} \mathrm{H}_{46} \mathrm{~N}_{2} \mathrm{O}$ & $\begin{array}{l}\text { Antioxidant effect and promotion of mitochondrial } \\
\text { biogenesis }\end{array}$ & Guo et al. [66] \\
\hline Tetrandrine & $\begin{array}{l}\text { Radix Stephaniae } \\
\text { Tetrandrae }\end{array}$ & $\mathrm{C}_{38} \mathrm{H}_{42} \mathrm{~N}_{2} \mathrm{O}_{6}$ & Regulation of glycolysis and energy metabolism & $\begin{array}{l}\text { Zhang et al. } \\
{[67]}\end{array}$ \\
\hline
\end{tabular}

10.3. Compound Prescriptions of TCM. Compound prescriptions are the main form of clinical TCM. After determining the treatment based on syndrome differentiation, a compound prescription is formulated by selecting the appropriate drug, determining the dosage, and combining two or more medicines according to the requirements of the basic structure of the prescription. The main objectives of these prescriptions are to enhance drug efficacy, produce synergistic drug effects, control the direction of multifunctional single herbs, expand the scope of treatment, improve drug adaptation to complex conditions, and control the toxic and side effects of drugs.

Clinically, most of the drugs used to treat $\mathrm{CHD}$ are compound prescriptions. The regulation of $\mathrm{CHD}$ by compound prescriptions involve the whole body, including the heart, brain, liver, kidney, lung, large intestine, muscle, and other viscera, and they improve the structure and quantity of mitochondria in each tissue $[39,74]$. In addition, compound prescriptions can treat $\mathrm{CHD}$ by protecting mitochondrial function, reducing antioxidant stress, improving mitochondrial lipid metabolism, and exerting anti-inflammatory effect. The compound prescriptions commonly used in TCM are listed in Table 6.

In summary, mitochondria are semiautonomous organelles that integrate the three basic life activities: material metabolism, energy metabolism, and genetic variation; they are also the place for intracellular respiration and energy conversion and participate in various important physiological and biochemical 
TABLE 5: Regulatory effects of single-herb traditional Chinese medicines on mitochondria.

\begin{tabular}{|c|c|c|c|}
\hline Type of TCM & Single herb & Mechanism of action & Reference \\
\hline Restoratives for invigorating qi & Radix Astragali & Promotion of mitochondrial bioenergetics & $\begin{array}{l}\text { Huang et al. } \\
{[68]}\end{array}$ \\
\hline Restoratives for invigorating qi & Rhodiola rosea & $\begin{array}{l}\text { Promotion of mitochondrial biogenesis and functions } \\
\text { Antioxidant and anti-inflammatory activities }\end{array}$ & $\begin{array}{l}\text { Zhuang et al. } \\
\text { [69] } \\
\text { Zhou et al. } \\
\text { [70] }\end{array}$ \\
\hline $\begin{array}{l}\text { Heat clearing Chinese } \\
\text { medicinal herbs }\end{array}$ & Silybum marianum & $\begin{array}{l}\text { Mitigation of oxidative stress and attenuation of reactive } \\
\text { fibrosis via TGF } \beta 1 / \mathrm{T} \beta \mathrm{R} / \mathrm{SMAD} 2 / 3 \text { signaling }\end{array}$ & $\begin{array}{l}\text { Vilahur et al. } \\
\text { [71] }\end{array}$ \\
\hline $\begin{array}{l}\text { Invigorating the blood and } \\
\text { removing blood stasis }\end{array}$ & $\begin{array}{l}\text { Salviae Miltiorrhizae } \\
\text { Radix et Rhizoma }\end{array}$ & Activation of the Nrf2-mediated antioxidant defense system & Li et al. [72] \\
\hline $\begin{array}{l}\text { The interior warming Chinese } \\
\text { medicinal herbs }\end{array}$ & Cortex Cinnamomi & Upregulation of mitochondrial biogenesis & $\begin{array}{l}\text { Song et al. } \\
\text { [73] }\end{array}$ \\
\hline
\end{tabular}

TABLE 6: Regulatory effects of compound prescriptions on mitochondria.

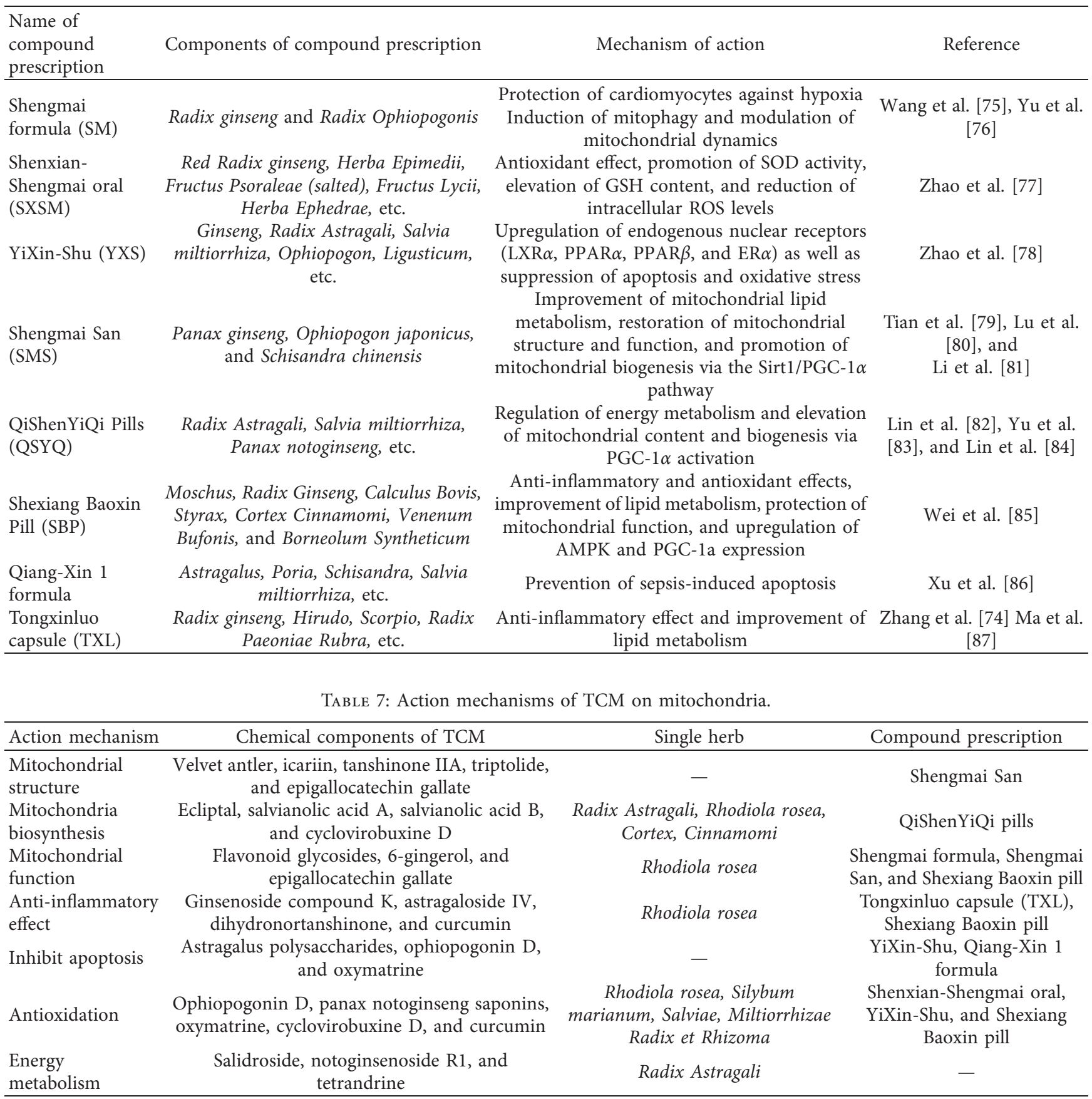


processes. Overall, TCM affects the processes of mitochondrial energy metabolism, apoptosis, and oxidative stress in multilevels via multitargets, and the same category of drugs has certain commonness and individuality. The mechanisms are summarized in Table 7.

\section{Conclusions and Perspectives}

CVD is the leading cause of death in China [2]. CHD is a relatively common type of CVD. At present, $\mathrm{CHD}$ has become a major global public health problem; although antithrombosis, anti-ischemia, and lipid-regulating interventional therapies and secondary preventions have been used to improve CHD symptoms and reduce the mortality and $\mathrm{HF}$ after percutaneous coronary intervention(PCI), no reflow after revascularization, depression after $\mathrm{CHD}, \mathrm{CHD}$ complications, and antithrombotic drug resistance still persist as clinical problems that need to be solved. At present, syndrome differentiation via a combination of modern medicine and TCM is the main method for treating CVD in China and abroad [88].

Coronary atherosclerosis or vasospasm leads to decreased myocardial blood perfusion and increased ischemic damage of cells. During the ischemic period, hypoxia causes inhibition of mitochondrial ATP synthesis and oxidative phosphorylation, making it difficult for cells to maintain normal ATP content. At the same time, under the condition of ischemia and hypoxia, excessive metabolites, such as lactic acid, pyruvate, phosphate, and other acids, accumulate in the myocardium and produce symptoms such as angina pectoris or chest tiredness. An evidence showed that mitochondrial dysfunction occurs in the early stage of CHD and mitochondrial autophagy occurs in the late stage, which involves the steady-state dynamic balance of mitochondria [89].

A growing number of studies showed that mitochondria play an important role in the cardiovascular system. Mitochondria can be used as targets for the treatment of CVDs [90]. Mutations in mtDNA affect CVD, leading to hypertension, atherosclerosis, and cardiomyopathy. However, TCM can regulate the structure and function of mitochondria by increasing electron transport and oxidative phosphorylation of mitochondria, thus regulating mitochondria-mediated apoptosis and reducing mitochondrial ROS to treat CVD.

At present, there are multiple forms of TCM used in the treatment of CVD, including its active components, single herbs, and compound prescriptions $[3,42]$. One review of 68 randomized controlled trials that included a total of 16171 patients revealed that, compared with blank control or placebo, TCM effectively reduces the severity of angina pectoris and MI; it also lowers blood pressure in patients with hypertension and improves cardiac function in patients with HF [91]. In most studies, the frequency of adverse effects was not higher for TCM than for controls or Western medicine [91]. However, the methodological quality of the majority of included studies was low; further studies using strictly designed randomized controlled trials are necessary to provide strong evidence [92]. Owing to the complexity of CVD pathogenesis, the action mechanism of TCM in the treatment of CVD is difficult to clarify. Moreover, mitochondria are the intracellular targets of many drugs, and there are extensive and complex interactions between mitochondria and related drugs [90].

TCM has the advantages of multitarget and multipathways [42, 93]. A large number of clinical experiences and studies have shown that TCM plays an important role in the prevention, treatment, and prognosis of CVD [93]. Previous studies by our team have shown that circRNAs are closely related to the pathological process of acute coronary syndrome via a mechanism that may be related to the up- or downregulation of circRNAs and miRNAs and the coexpression of circRNA-miRNA [94]. In addition, through literature review, we consider that the circRNA-miRNAmRNA network may be a new regulatory mechanism for TCM to effectively treat CVD [93]. Besides, TCM has been shown to improve the morphology and structure of mitochondria and participate in a series of metabolic processes, including regulation of energy metabolism, inhibition of apoptosis, and reduction of oxygen free radical production in mitochondria. There is a certain correlation between the intracellular targets of TCM and mitochondria.

Furthermore, we should treat diseases according to syndrome differentiation and reasonably choose TCM based on the basic theory of TCM. Integrating TCM with Western medicine, an unprecedented task in today's world, would provide a new medical model with unique advantages that can play an important role in the treatment of diseases [95]. Some experiments have confirmed the efficacy of combining TCM with Western medicine for the treatment of angina pectoris [96], and evidence for using TCM for the treatment of other CVDs is also increasing [3]. The combination of TCM and Western medicine is an attractive avenue for therapeutic intervention in CVD, and it may be the best scheme for CVD treatment. Thus, developing a strategy for integrating TCM with Western medicine will greatly contribute to human health care [95].

\section{Data Availability}

This review article is based on some previous studies of the authors on the relationship between mitochondria and cardiovascular diseases and the role of traditional Chinese medicine in the treatment of cardiovascular diseases. Previously reported studies were used to support this study and are available at doi: $10.1155 / 2015 / 143145$, doi: $10.1155 / 2020 /$ 1584052, doi: $10.1155 / 2020 / 8048691$, etc. In addition, the results obtained through extensive literature review provide strong support for the article. These prior studies are cited at relevant places within the text as references.

\section{Conflicts of Interest}

The authors declare that they have no conflicts of interest regarding the publication of this paper.

\section{Acknowledgments}

This work was supported by the Key Scientific Research Projects of Higher Education Institutions in Henan Province 
(nos. 2006320035 and 19A360032) and Scientific and Technological Research Projects in Henan Province (nos. 182102310182 and 192102310319).

\section{References}

[1] K. J. Foreman, N. Marquez, A. Dolgert et al., "Forecasting life expectancy, years of life lost, and all-cause and cause-specific mortality for 250 causes of death: reference and alternative scenarios for 2016-40 for 195 countries and territories," The Lancet, vol. 392, no. 10159, pp. 2052-2090, 2018.

[2] D. Zhao, J. Liu, M. Wang, X. Zhang, and M. Zhou, "Epidemiology of cardiovascular disease in China: current features and implications," Nature Reviews Cardiology, vol. 16, no. 4, pp. 203-212, 2019.

[3] X. Xiong, F. Borrelli, A. de Sá Ferreira, T. Ashfaq, and B. Feng, "Herbal medicines for cardiovascular diseases," Evidence Based Complementary and Alternative Medicine, vol. 2014, Article ID 809741, 2014.

[4] J. B. Spinelli and M. C. Haigis, "The multifaceted contributions of mitochondria to cellular metabolism," Nature Cell Biology, vol. 20, no. 7, pp. 745-754, 2018.

[5] F. J. Bock and S. W. G. Tait, "Mitochondria as multifaceted regulators of cell death," Nature Reviews Molecular Cell Biology, vol. 21, no. 2, pp. 85-100, 2020.

[6] K. Boengler, M. Kosiol, M. Mayr, R. Schulz, and S. Rohrbach, "Mitochondria and ageing: role in heart, skeletal muscle and adipose tissue," Journal of Cachexia, Sarcopenia and Muscle, vol. 8, no. 3, pp. 349-369, 2017.

[7] J. Szymański, J. Janikiewicz, B Michalska et al., "Interaction of mitochondria with the endoplasmic reticulum and plasma membrane in calcium homeostasis, lipid trafficking and mitochondrial structure," International Journal of Molecular Sciences, vol. 18, no. 7, 2017.

[8] E. J. Lesnefsky, Q. Chen, and C. L. Hoppel, "Mitochondrial metabolism in aging heart," Circulation Research, vol. 118, no. 10, pp. 1593-1611, 2016.

[9] B. Martín-Fernández and R. Gredilla, "Mitochondria and oxidative stress in heart aging," Age, vol. 38, no. 4, pp. 225-238, 2016.

[10] S. Herzig, R. J. Shaw, and R. J. Shaw, "AMPK: guardian of metabolism and mitochondrial homeostasis," Nature Reviews Molecular Cell Biology, vol. 19, no. 2, pp. 121-135, 2018.

[11] G. Siasos, V. Tsigkou, M. Kosmopoulos et al., "Mitochondria and cardiovascular diseases-from pathophysiology to treatment," Annals of Translational Medicine, vol. 6, no. 12, p. 256, 2018.

[12] J. N. Meyer, T. C. Leuthner, and A. L. Luz, "Mitochondrial fusion, fission, and mitochondrial toxicity," Toxicology, vol. 293, pp. 42-53, 2017.

[13] K. Palikaras and N. Tavernarakis, "Mitochondrial homeostasis: the interplay between mitophagy and mitochondrial biogenesis," Experimental Gerontology, vol. 56, pp. 182-188, 2014.

[14] N. Pfanner, B. Warscheid, and N. Wiedemann, "Mitochondrial proteins: from biogenesis to functional networks," Nature Reviews.Molecular Cell Biology, vol. 20, pp. 267-284, 2019.

[15] P. E. Morales, C. Arias-Durán, Y. Ávalos-Guajardo et al., "Emerging role of mitophagy in cardiovascular physiology and pathology," Molecular Aspects of Medicine, vol. 71, Article ID 100822, 2020.

[16] C. Vásquez-Trincado, I. García-Carvajal, C. Pennanen et al., "Mitochondrial dynamics, mitophagy and cardiovascular disease," The Journal of Physiology, vol. 594, no. 3, pp. 509-525, 2016.

[17] S. J. Forrester, D. S. Kikuchi, M. S. Hernandes, Q. Xu, and K. K. Griendling, "Reactive oxygen species in metabolic and inflammatory signaling," Circulation Research, vol. 122, no. 6, pp. 877-902, 2018.

[18] S. Cadenas, "ROS and redox signaling in myocardial ischemia-reperfusion injury and cardioprotection," Free Radical Biology \& Medicine, vol. 117, Article ID 76, 89 pages, 2018.

[19] E. Murphy, H. Ardehali, R. S. Balaban et al., "Mitochondrial function, biology, and role in disease," Circulation Research, vol. 118, no. 12, pp. 1960-1991, 2016.

[20] M. Pecoraro, A. Pinto, and A. Popolo, "Mitochondria and cardiovascular disease: a brief account," Critical Reviews in Eukaryotic Gene Expression, vol. 29, no. 4, pp. 295-304, 2019.

[21] J. R. Mercer, K.-K. Cheng, N. Figg et al., "DNA damage links mitochondrial dysfunction to atherosclerosis and the metabolic syndrome," Circulation Research, vol. 107, no. 8, pp. 1021-1031, 2010.

[22] D. A. Chistiakov, I. A. Sobenin, Y. V. Bobryshev et al., "Mitochondrial dysfunction and mitochondrial DNA mutations in atherosclerotic complications in diabetes," World Journal of Cardiology, vol. 4, no. 5, pp. 148-156, 2012.

[23] S. K. Roy Chowdhury, G. V. Sangle, X. Xie, G. L. Stelmack, A. J. Halayko, and G. X. Shen, "Effects of extensively oxidized low-density lipoprotein on mitochondrial function and reactive oxygen species in porcine aortic endothelial cells," American Journal of Physiology-Endocrinology and Metabolism, vol. 298, no. 1, pp. E89-E98, 2010.

[24] A. Devarajan, N. Bourquard, S. Hama et al., "Paraoxonase 2 deficiency alters mitochondrial function and exacerbates the development of atherosclerosis," Antioxidants \& Redox Signaling, vol. 14, no. 3, pp. 341-351, 2011.

[25] C. M Harrison, M. Pompilius, K. E. Pinkerton, and S. W Ballinger, "Mitochondrial oxidative stress significantly influences atherogenic risk and cytokine-induced oxidant production," Environmental Health Perspectives, vol. 119, no. 5, pp. 676-681, 2011.

[26] D. J. Tyrrell, M. G. Blin, J. Song et al., "Age-associated mitochondrial dysfunction accelerates atherogenesis," Circulation Research, vol. 126, no. 3, pp. 298-314, 2020.

[27] A. N. Orekhov, A. V. Poznyak, I. A. Sobenin et al., "Mitochondrion as a selective target for treatment of atherosclerosis: role of mitochondrial DNA mutations and defective mitophagy in the pathogenesis of atherosclerosis and chronic inflammation," Current Neuropharmacology, vol. 18, 2019.

[28] V. Lahera, N. de Las Heras, A. López-Farré, W. Manucha, and L. Ferder, "Role of mitochondrial dysfunction in hypertension and obesity," Current Hypertension Reports, vol. 19, no. 2, p. 11, 2017.

[29] S. H. H. Chan, C.-A. Wu, K. L. H. Wu, Y.-H. Ho, A. Y. W. Chang, and J. Y. H. Chan, "Transcriptional upregulation of mitochondrial uncoupling protein 2 protects against oxidative stress-associated neurogenic hypertension," Circulation Research, vol. 105, no. 9, pp. 886-896, 2009.

[30] J. D. Widder, D. Fraccarollo, P. Galuppo et al., "Attenuation of angiotensin II-induced vascular dysfunction and hypertension by overexpression of thioredoxin 2," Hypertension, vol. 54, no. 2, pp. 338-344, 2009.

[31] S. H. H. Chan, K. L. H. Wu, A. Y. W. Chang, M.-H. Tai, and J. Y. H. Chan, "Oxidative impairment of mitochondrial electron transport chain complexes in rostral ventrolateral medulla contributes to neurogenic hypertension," Hypertension, vol. 53, no. 2, pp. 217-227, 2009. 
[32] Q. Qiu, R. Li, P. Jiang et al., "Mitochondrial tRNA mutations are associated with maternally inherited hypertension in two Han Chinese pedigrees," Human Mutation, vol. 33, no. 8, pp. 1285-1293, 2012.

[33] M. C. Zimmerman, E. Lazartigues, R. V. Sharma, and R. L. Davisson, "Hypertension caused by angiotensin II infusion involves increased superoxide production in the central nervous system," Circulation Research, vol. 95, no. 2, pp. 210-216, 2004.

[34] M.-G. Perrelli, P. Pagliaro, and C. Penna, "Ischemia/reperfusion injury and cardioprotective mechanisms: role of mitochondria and reactive oxygen species," World Journal of Cardiology, vol. 3, no. 6, pp. 186-200, 2011.

[35] C. Penna, M.-G. Perrelli, and P. Pagliaro, "Mitochondrial pathways, permeability transition pore, and redox signaling in cardioprotection: therapeutic implications," Antioxidants \& Redox Signaling, vol. 18, no. 5, pp. 556-599, 2013.

[36] N. Lu, Y. Sun, and X. Zheng, "Orientin-induced cardioprotection against reperfusion is associated with attenuation of mitochondrial permeability transition," Planta Medica, vol. 77, no. 10, pp. 984-991, 2011.

[37] M. G. Rosca, E. J. Vazquez, J. Kerner et al., "Cardiac mitochondria in heart failure: decrease in respirasomes and oxidative phosphorylation," Cardiovascular Research, vol. 80, no. 1, pp. 30-39, 2008.

[38] L. A. Kiyuna, R. P. E. Albuquerque, C. H. Chen et al., "Targeting mitochondrial dysfunction and oxidative stress in heart failure: challenges and opportunities," Free Radical Biology \& Medicine, vol. 129, pp. 155-168, 2018.

[39] G. Faerber, F. Barreto-Perreia, M. Schoepe et al., "Induction of heart failure by minimally invasive aortic constriction in mice: reduced peroxisome proliferator-activated receptor $\gamma$ coactivator levels and mitochondrial dysfunction," The Journal of Thoracic and Cardiovascular Surgery, vol. 141, no. 2, pp. 492-500, 2011.

[40] G. Karamanlidis, V. Bautista-Hernandez, F. Fynn-Thompson, P. del Nido, and R. Tian, "Impaired mitochondrial biogenesis precedes heart failure in right ventricular hypertrophy in congenital heart disease," Circulation: Heart Failure, vol. 4, no. 6, pp. 707-713, 2011.

[41] R. Tian, W. S. Colucci, Z. Arany et al., "Unlocking the secrets of mitochondria in the cardiovascular system," Circulation, vol. 140, no. 14, pp. 1205-1216, 2019.

[42] P. Hao, F. Jiang, J. Cheng, L. Ma, Y. Zhang, and Y. Zhao, "Traditional Chinese medicine for cardiovascular disease," Journal of the American College of Cardiology, vol. 69, no. 24, pp. 2952-2966, 2017.

[43] S. Lu, Y. Luo, P. Zhou, K. Yang, G. Sun, and X. Sun, "Ginsenoside compound $\mathrm{K}$ protects human umbilical vein endothelial cells against oxidized low-density lipoprotein-induced injury via inhibition of nuclear factor- $\kappa \mathrm{B}, \mathrm{p} 38$, and JNK MAPK pathways," Journal of Ginseng Research, vol. 43, no. 1, pp. 95-104, 2019.

[44] S. Zhang, F. Tang, Y. Yang et al., "Astragaloside IV protects against isoproterenol-induced cardiac hypertrophy by regulating NF- $\kappa \mathrm{B} / \mathrm{PGC}-1 \alpha$ signaling mediated energy biosynthesis," PLoS One, vol. 10, no. 3, Article ID e0118759, 2015.

[45] L. Gong, H. Chang, J. Zhang, G. Guo, J. Shi, and H. Xu, "Astragaloside IV protects rat cardiomyocytes from hypoxiainduced injury by down-regulation of miR-23a and miR-92a," Cellular Physiology and Biochemistry, vol. 49, no. 6, pp. 2240-2253, 2018.

[46] Z. Dong, P. Zhao, M. Xu et al., "Astragaloside IV alleviates heart failure via activating PPAR $\alpha$ to switch glycolysis to fatty acid $\beta$-oxidation," Scientific Reports, vol. 7, p. 2691, 2017.
[47] D. Liu, L. Chen, J. Zhao, and K. Cui, "Cardioprotection activity and mechanism of Astragalus polysaccharide in vivo and in vitro," International Journal of Biological Macromolecules, vol. 111, pp. 947-952, 2018.

[48] T. Zheng, X. Yang, D. Wu et al., "Salidroside ameliorates insulin resistance through activation of a mitochondria-associated AMPK/PI3K/Akt/GSK3 $\beta$ pathway," British Journal of Pharmacology, vol. 172, no. 13, pp. 3284-3301, 2015.

[49] X. Huang, Y. Wang, Y. Wang, D. L. Ophiopogonin, J. Wang, and Y. Gao, "Ophiopogonin D reduces myocardial ischemiareperfusion injury via upregulating CYP2J3/EETs in rats," Cellular Physiology and Biochemistry, vol. 49, no. 4, pp. 1646-1658, 2018.

[50] A. Yang, A. Kumar, D. Kumar et al., "Ecliptal, a promising natural lead isolated from Eclipta alba modulates adipocyte function and ameliorates metabolic syndrome," Toxicology and Applied Pharmacology, vol. 338, pp. 134-147, 2018.

[51] X. Xiao, S. Xu, L. Li et al., "The effect of velvet antler proteins on cardiac microvascular endothelial cells challenged with ischemia-hypoxia," Frontiers in Pharmacology, vol. 8, p. 601, 2017.

[52] B. Wu, J.-Y. Feng, L.-M. Yu et al., "Icariin protects cardiomyocytes against ischaemia/reperfusion injury by attenuating sirtuin 1-dependent mitochondrial oxidative damage," British Journal of Pharmacology, vol. 175, no. 21, pp. 41374153, 2018.

[53] M. Zhang, Y. Guan, J. Xu et al., "Evaluating the protective mechanism of panax notoginseng saponins against oxidative stress damage by quantifying the biomechanical properties of single cell," Analytica Chimica Acta, vol. 1048, pp. 186-193, 2019.

[54] Z. Zhou, J. Wang, Y. Song et al., "Panax notoginseng saponins attenuate cardiomyocyte apoptosis through mitochondrial pathway in natural aging rats," Phytotherapy Research, vol. 32, no. 2, pp. 243-250, 2018.

[55] K. He, L. Yan, C.-S. Pan et al., "ROCK-dependent ATP5D modulation contributes to the protection of notoginsenoside NR1 against ischemia-reperfusion-induced myocardial injury," American Journal of Physiology-Heart and Circulatory Physiology, vol. 307, no. 12, pp. H1764-H1776, 2014.

[56] J.-Yi Zhang, M. Wang, R.-Y. Wang et al., "Salvianolic acid A ameliorates arsenic trioxide-induced cardiotoxicity through decreasing cardiac mitochondrial injury and promotes its anticancer activity," Frontiers in Pharmacology, vol. 9, p. 487, 2018.

[57] Y. Pan, W. Zhao, and D. Zhao, "Salvianolic acid B improves mitochondrial function in 3T3-L1 adipocytes through a pathway involving PPAR $\gamma$ coactivator- $1 \alpha$ (PGC- $1 \alpha)$," Frontiers in Pharmacology, vol. 9, p. 671, 2018.

[58] Z. Zhang, H. He, and Y. Qiao, "Tanshinone IIA pretreatment protects $\mathrm{H} 9 \mathrm{c} 2$ cells against anoxia/reoxygenation injury involvement of the translocation of bcl-2 to mitochondria

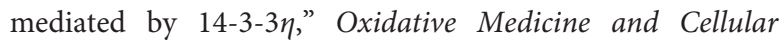
Longevity, vol. 2018, Article ID 3583921, 2018.

[59] X. Wu, H. Gao, Y. Hou et al., "Dihydronortanshinone, a natural product, alleviates LPS-induced inflammatory response through NF- $\kappa \mathrm{B}$, mitochondrial ROS, and MAPK pathways," Toxicology and Applied Pharmacology, vol. 355, pp. 1-8, 2018.

[60] H. Li, A. Sureda, H. P. Devkota et al., "Curcumin, the golden spice in treating cardiovascular diseases," Biotechnology Advances, vol. 38, Article ID 107343, 2019.

[61] G. Luan, Y. Wang, Z. Wang et al., "Flavonoid glycosides from fenugreek seeds regulate glycolipid metabolism by improving 
mitochondrial function in 3T3-L1 adipocytes in vitro," Journal of Agricultural and Food Chemistry, vol. 66, no. 12, pp. 3169-3178, 2018.

[62] Li Liu, L. Yao, S. Wang et al., "Gingerol improves ectopic lipid accumulation, mitochondrial .dysfunction, and insulin resistance in skeletal muscle of ageing rats: dual stimulation of the AMPK/PGC- $1 \alpha$ signaling pathway via plasma adiponectin and muscular AdipoR1," Molecular Nutrition and Food Research, vol. 63, no. 6, Article ID e1800649, 2019.

[63] Y. Xi, W. Wang, L. Wang et al., "Triptolide induces p53dependent cardiotoxicity through mitochondrial membrane permeabilization in cardiomyocytes," Toxicology and Applied Pharmacology, vol. 355, pp. 269-285, 2018.

[64] Y.-Y. Zhang, M. Yi, Y.-P. Huang et al., "Oxymatrine ameliorates doxorubicin-induced cardiotoxicity in rats," Cellular Physiology and Biochemistry, vol. 43, no. 2, pp. 626-635, 2017.

[65] J. Nan, C. Nan, J. Ye et al., "EGCG protects cardiomyocytes against hypoxia-reperfusion injury through inhibition of OMA1 activation," Journal of Cell Science, vol. 132, 2019.

[66] Q. Guo, J. Guo, R. Yang et al., "Cyclovirobuxine D attenuates doxorubicin-induced cardiomyopathy by suppression of oxidative damage and mitochondrial biogenesis impairment," Oxidative Medicine and Cellular Longevity, vol. 2015, Article ID 151972, 2015.

[67] T.-J. Zhang, R.-X. Guo, X. Li, Y.-W. Wang, and Y.-J. Li, "Tetrandrine cardioprotection in ischemia-reperfusion (I/R) injury via JAK3/STAT3/Hexokinase II," European Journal of Pharmacology, vol. 813, pp. 153-160, 2017.

[68] Y. Huang, K. Kwan, K. Leung et al., "The extracts and major compounds derived from astragali radix alter mitochondrial bioenergetics in cultured cardiomyocytes: comparison of various polar solvents and compounds," International Journal of Molecular Sciences, vol. 19, no. 6, p. 1574, 2018.

[69] W. Zhuang, L. Yue, X. Dang et al., "Rosenroot (rhodiola): potential applications in aging-related diseases," Aging and Disease, vol. 10, no. 1, pp. 134-146, 2019.

[70] Q. Chen, X. Han, R. Li et al., "Anti-atherosclerosis of oligomeric proanthocyanidins from Rhodiola rosea on rat model via hypolipemic, antioxidant, anti-inflammatory activities together with regulation of endothelial function," Phytomedicine, vol. 51, pp. 171-180, 2018.

[71] G. Vilahur, L. Casaní, E. Peña et al., "Silybum marianum provides cardioprotection and limits adverse remodeling post-myocardial infarction by mitigating oxidative stress and reactive fibrosis," International Journal of Cardiology, vol. 270, no. 270, pp. 28-35, 2018.

[72] G.-H. Li, Y.-R. Li, and P. Jiao, "Therapeutic potential of salviae miltiorrhizae radix et rhizoma against human diseases based on activation of nrf2-mediated antioxidant defense system: bioactive constituents and mechanism of action," Oxidative Medicine and Cellular Longevity, vol. 2018, Article ID 7309073, 2018.

[73] M. Y. Song, S. Y. Kang, A. Kang, J. H. Hwang, Y.-K. Park, and H. W. Jung, "Cinnamomum cassia prevents high-fat dietinduced obesity in mice through the increase of muscle energy," The American Journal of Chinese Medicine, vol. 45, no. 5, pp. 1017-1031, 2017.

[74] M. Zhang, Y. Liu, and M. Xu, "Carotid artery plaque intervention with Tongxinluo capsule(CAPITAL): a multicenter randomized double-blind parallel-group placebo-controlled study," Science Reports, vol. 9, no. 1, p. 4545, 2019.

[75] Y. Wang, Y. Zhao, W. Jiang et al., "iTRAQ-based proteomic analysis reveals recovery of impaired mitochondrial function in ischemic myocardium by shenmai formula," Journal of Proteome Research, vol. 17, no. 2, pp. 794-803, 2018.

[76] J. Yu, Y. Li, X. Liu et al., "Mitochondrial dynamics modulation as a critical contribution for Shenmai injection in attenuating hypoxia/reoxygenation injury," Journal of Ethnopharmacology, vol. 237, pp. 9-19, 2019.

[77] Y. Zhao, X. Zhang, J. Luan et al., "Shenxian-shengmai oral liquid reduces myocardial oxidative stress and protects myocardium from ischemia-reperfusion injury," Cellular Physiology and Biochemistry, vol. 48, no. 6, pp. 2503-2516, 2018.

[78] Y. Zhao, L. Xu, Z. Qiao et al., "YiXin-Shu, a ShengMai-Sanbased traditional Chinese medicine formula, attenuates myocardial ischemia/reperfusion injury by suppressing mitochondrial mediated apoptosis and upregulating liver-Xreceptor $\alpha$," Science Reports, vol. 6, p. 23025, 2016.

[79] J. Tian, W. Tang, M. Xu et al., "Shengmai san alleviates diabetic cardiomyopathy through improvement of mitochondrial lipid metabolic disorder," Cellular Physiology and Biochemistry, vol. 50, no. 5, pp. 1726-1739, 2018.

[80] X. Lu, Lu Zhang, P. Li et al., "The protective effects of compatibility of Aconiti Lateralis Radix Praeparata and Zingiberis Rhizoma on rats with heart failure by enhancing mitochondrial biogenesis via Sirt1/PGC- $1 \alpha$ pathway," Biomedicine \& Pharmacotherapy, vol. 92, pp. 651-660, 2017.

[81] F. Li, X.-X. Fan, C. Chu, Y. Zhang, J.-P. Kou, and B.-Y. Yu, “A strategy for optimizing the combination of active components based on Chinese medicinal formula sheng-mai-san for myocardial ischemia," Cellular Physiology and Biochemistry, vol. 45, no. 4, pp. 1455-1471, 2018.

[82] S.-Q. Lin, X.-H. Wei, P. Huang et al., "QiShenYiQi Pills prevents cardiac ischemia-reperfusion injury via energy modulation," International Journal of Cardiology, vol. 168, no. 2, pp. 967-974, 2013.

[83] J. Yu, W. Zhang, Y. Zhang et al., "A critical courier role of volatile oils from Dalbergia odorifera for cardiac protection in vivo by QiShenYiQi,” Science Reports, vol. 7, no. 1, p. 7353, 2017.

[84] S. Lin, X. Wu, L. Tao et al., "The metabolic effects of traditional Chinese medication qiliqiangxin on H9C2 cardiomyocytes," Cellular Physiology and Biochemistry, vol. 37, no. 6, pp. 2246-2256, 2015.

[85] D. Wei, N. Zheng, and L. Zheng, "Shexiang baoxin pill corrects metabolic disorders in a rat model of metabolic syndrome by targeting mitochondria," Frontiers in Pharmacology, vol. 9, p. 137, 2018.

[86] X. Xu, Q. Liu, and S. He, "Qiang-xin 1 formula prevents sepsis-induced apoptosis in murine cardiomyocytes by suppressing endoplasmic reticulum- and mitochondria-associated pathways," Frontiers in Pharmacology, vol. 9, p. 818, 2018.

[87] J. Ma, L. Qiao, and L. Meng, “Tongxinluo may stabilize atherosclerotic plaque via multiple mechanisms scanning by genechip," Biomedicine \& Pharmacotherapy, vol. 113, Article ID 108767, 2019.

[88] F. Lin, J. Wang, X.-J. Xiong et al., "Chinese medical syndrome distribution laws of mitochondrial diseases based on combination of disease and syndrome," Zhongguo Zhong Xi Yi Jie He ZaZhi, vol. 36, no. 11, pp. 1381-1384, 2016.

[89] J. Wang, F. Lin, L. L. Guo et al., "Cardiovascular disease, mitochondria, and traditional Chinese medicine," Evidence Based Complementary and Alternative Medicine, vol. 2015, Article ID 143145, 2015.

[90] M. Bonora, M. R. Wieckowski, D. A. Sinclair, G. Kroemer, P. Pinton, and L. Galluzzi, "Targeting mitochondria for 
cardiovascular disorders: therapeutic potential and obstacles," Nature Reviews Cardiology, vol. 16, no. 1, pp. 33-55, 2019.

[91] P.-P. Hao, F. Jiang, Y.-G. Chen et al., "Erratum: traditional Chinese medication for cardiovascular disease," Nature Reviews Cardiology, vol. 12, no. 6, p. 318, 2015.

[92] X. Xiong, "Integrating traditional Chinese medicine into Western cardiovascular medicine: an evidence-based approach," Nature Reviews Cardiology, vol. 12, no. 6, p. 374, 2015.

[93] F. Lin, Y. Yang, Q. Guo et al., "Analysis of the molecular mechanism of acute coronary syndrome based on circRNAmiRNA network regulation," Evidence Based Complementary and Alternative Medicine, vol. 2020, Article ID 1584052, 2020.

[94] F. Lin, H. W. Chen, G. A. Zhao et al., "Advances in research on the circRNA-miRNA-mRNA network in coronary heart disease treated with traditional Chinese medicine," Evidence Based Complementary and Alternative Medicine, vol. 2020, Article ID 8048691, 2020.

[95] J. Wang and X. Xiong, "Current situation and perspectives of clinical study in integrative medicine in China," Evidence Based Complementary and Alternative Medicine, vol. 2012, Article ID 268542, 2012.

[96] X.-J. Xiong, Z. Wang, and J. Wang, "Innovative strategy in treating angina pectoris with Chinese patent medicines by promoting blood circulation and removing blood stasis: experience from combination therapy in Chinese medicine," Current Vascular Pharmacology, vol. 13, no. 4, pp. 540-553, 2015. 